\title{
Hippocampal glutamate-glutamine (Glx) in adults with Down syndrome: a preliminary study using in vivo proton magnetic resonance spectroscopy ( ${ }^{1} \mathrm{H}$ MRS)
}

Giles MY Tan ${ }^{1,2^{*}}$, Felix Beacher ${ }^{1}$, Eileen Daly ${ }^{1}$, Jamie Horder ${ }^{1}$, Verinder Prasher ${ }^{3}$, Maria-Luisa Hanney ${ }^{4}$, Robin Morris ${ }^{5}$, Simon Lovestone ${ }^{6}$, Kieran C Murphy ${ }^{7}$, Andrew Simmons ${ }^{8,9}$ and Declan GM Murphy ${ }^{1,9}$

\begin{abstract}
Background: Down syndrome (DS), or trisomy 21, is one of the most common autosomal mutations. People with DS have intellectual disability (ID) and are at significantly increased risk of developing Alzheimer's disease (AD). The biological associates of both ID and AD in DS are poorly understood, but glutamate has been proposed to play a key role. In non-DS populations, glutamate is essential to learning and memory and glutamate-mediated excitotoxicity has been implicated in AD. However, the concentration of hippocampal glutamate in DS individuals with and without dementia has not previously been directly investigated. Proton magnetic resonance spectroscopy ('H MRS) can be used to measure in vivo the concentrations of glutamate-glutamine (Glx). The objective of the current study was to examine the hippocampal Glx concentration in non-demented DS (DS-) and demented DS (DS+) individuals.
\end{abstract}

Methods: We examined 46 adults with DS (35 without dementia and 11 with dementia) and 39 healthy controls (HC) using ${ }^{1} H$ MRS and measured their hippocampal Glx concentrations.

Results: There was no significant difference in the hippocampal Glx concentration between DS+ and DS-, or between either of the DS groups and the healthy controls. Also, within DS, there was no significant correlation between hippocampal Glx concentration and measures of overall cognitive ability. Last, a sample size calculation based on the effect sizes from this study showed that it would have required 6,257 participants to provide $80 \%$ power to detect a significant difference between the groups which would indicate that there is a very low likelihood of a type 2 error accounting for the findings in this study.

Conclusions: Individuals with DS do not have clinically detectable differences in hippocampal Glx concentration. Other pathophysiological processes likely account for ID and AD in people with DS.

Keywords: Down syndrome, Intellectual disability, Alzheimer's disease, Dementia, Magnetic resonance spectroscopy, ${ }^{1} \mathrm{H}$ MRS, Hippocampus, Glutamate-glutamine (GIx)

\footnotetext{
* Correspondence: giles.tan@kcl.ac.uk

'Sackler Institute for Translational Neurodevelopment, Department of

Forensic and Neurodevelopmental Sciences, Institute of Psychiatry, King's

College London, London, UK

${ }^{2}$ Southern Health NHS Foundation Trust, North Hampshire Community

Learning Disability Service, Winchester, Hampshire, UK

Full list of author information is available at the end of the article
} 


\section{Background}

Down syndrome (DS) is one of the most common chromosomal disorders and is caused by trisomy 21 or a translocation involving chromosome 21 [1]. A prominent feature of DS is intellectual disability (ID) and there is an increased risk of developing Alzheimer's disease (AD) [2]. For example, it has been estimated that the prevalence of $\mathrm{AD}$ in DS increases dramatically from $11 \%$ between ages 40 to 49 to as high as $77 \%$ between 60 and 69 [3-5].

The underlying cause(s) for both the ID and AD is likely to be multifactorial. For instance, it has been hypothesised that in the DS brain, the presence of an extra copy of the amyloid precursor protein (APP) gene (which is localised to chromosome 21) leads to abnormalities in amyloid precursor protein processing in neuronal membranes and subsequently to amyloid plaques and $\mathrm{AD}$ [6]. In addition, reduced levels of serotonin (5HT) and gammaaminobutyric acid (GABA) have been observed in foetal DS brains [7]. Further, it has been reported that in a DS mouse model, the selective serotonin reuptake inhibitor fluoxetine normalises hippocampal neurogenesis and performance on a hippocampus-dependent memory task [8] - whereas excessive GABA-mediated inhibition impairs the induction of long-term potentiation (LTP) and memory processes in the same region [9]. We previously reported our findings of myo-inositol (mI), N-acetylaspartate (NAA), choline-containing compounds (Cho) and creatine and phosphocreatine $(\mathrm{Cr}+\mathrm{Pr})$ from the current study sample in an earlier paper which showed that adults with DS have a significantly increased hippocampal concentration of myo-inositol as compared to healthy controls [10] and that this is associated with reduced cognitive ability. Increased concentration of myo-inositol within individuals with DS may also be associated with increased risk for AD [11]. Hence, there is increasing evidence that a number of neurochemical systems likely contribute to the DS cognitive phenotype-but there have been relatively few studies on the putative role of glutamate within individuals with DS.

Normal cognitive function (including attention, learning, memory and executive processes) is supported by a number of neurotransmitters - central to which is the glutamatergic system [12]. Glutamate is the primary excitatory neurotransmitter in the brain and is involved in synaptic transmission, plasticity and excitotoxicity [13]. Enhanced glutamate release from presynaptic neurons and subsequent activation of postsynaptic alpha-amino3-hydroxy-5-methyl-4-isoxazole-propionic acid (AMPA) and N-methyl-D-aspartate (NMDA) glutamate receptors are crucial for LTP $[14,15]$ and successful performance of numerous higher cognitive functions-including memory and learning [16,17]. Also, it has been suggested that within the non-DS population, glutamate-mediated excitotoxicity contributes to the neurodegeneration and cognitive dysfunction typically observed in people with AD [18-21].

The importance of this neurotransmitter pathway in non-DS people with AD is further supported by evidence from clinical trials in these populations which showed the efficacy of drugs that target glutamatergic neurotransmission. For example, it has been reported that memantine (an NMDA receptor antagonist) reduces hippocampal glutamate concentration [22] and improves the behavioural, cognitive and functional symptoms in people with $\mathrm{AD}$ [23]. Therefore, there is evidence that reduction in hippocampal glutamate concentrations is associated with improved cognitive function by modulating glutamatergic neurotransmission and reducing excitotoxicity in non-DS people with AD.

Further, murine models of DS suggest 1) that there is an imbalance between hippocampal inhibitory and excitatory inputs $[9,24], 2)$ there are changes in the levels of the glutamate transporter and vesicular glutamate transporter 1 (VGLUT1) [25] and 3) that there are impairments in signalling mechanisms downstream of the NMDA receptor [26]. Therefore, based on the above considered evidence, it is possible that abnormalities in glutamate metabolism may partly account for both the ID and increased risk for $\mathrm{AD}$ in people with $\mathrm{DS}$.

There is initial indirect evidence (from studies of platelets and fibroblasts) that glutamate uptake may be significantly decreased in DS individuals [27]. There have also been a small number of postmortem studies. For instance, some have reported no difference in glutamine or glutamate concentration in the frontal lobes of foetal DS brains as compared to controls [7]. In contrast, some (but not all) autopsy studies of adult DS brains reported decreased glutamate levels in the hippocampus [28] or no differences in the temporal lobes [29] or frontal lobes [30]. These studies were important first steps-but postmortem studies have inherent (and significant) limitations for measuring glutamate, and this prior work was confounded by medication effects. Also, to date, there are few studies that have directly examined in vivo brain glutamate in DS.

\section{Proton magnetic resonance spectroscopy}

Proton magnetic resonance spectroscopy $\left({ }^{1} \mathrm{H}\right.$ MRS) can be used to measure brain concentrations of glutamate-glutamine (Glx), mI, NAA, Cho and $\mathrm{Cr}+\mathrm{PCr}[31,32]$. In excitatory neurotransmission, glutamate is released into the synaptic cleft and is then rapidly removed by uptake into astrocytes (where it is converted into glutamine) and subsequently transported back to the presynaptic neuron for reconversion to glutamate [33,34]. The Glx signal on ${ }^{1} \mathrm{H}$ MRS can therefore be used as a measure for central glutamatergic neurotransmission-albeit without sufficient resolution to determine which particular component of the Glx cycle is abnormal. 
There are only two prior ${ }^{1} \mathrm{H}$ MRS studies of Glx in people with DS. These reported a significant decrease in Glx concentration within DS frontal lobe [35] - but no difference in the temporal lobe [36]. Those two studies were valuable first steps, but they only included children and did not examine brain regions most implicated in $\mathrm{AD}$. Therefore, to explore the putative role that the glutamatergic neurotransmitter system plays in ID and risk of AD in DS, in vivo studies of adults are required.

The hippocampus may be of particular relevance in people with DS as its volume has been reported to be disproportionately reduced ([37,38] and see review [39]), and it is the brain region most vulnerable to the neuropathological changes of $\mathrm{AD}[40,41]$. To the best of our knowledge, there are no studies to date that have evaluated the in vivo concentrations of hippocampal Glx in DS adults. Therefore, given the potential contributory role of abnormalities in glutamatergic neurotransmission to both ID and AD in people with DS, we investigated the hippocampal concentration of Glx in DS adults with (DS+) and without (DS-) dementia using ${ }^{1} \mathrm{H}$ MRS.

\section{Methods}

\section{Participants}

We included 85 adults: 46 DS individuals (35 DSand $11 \mathrm{DS}+$ ) and 39 healthy controls (Table 1). Individuals with DS were recruited from cohorts in London, Birmingham and Newcastle upon Tyne, England. Karyotyping was used to assess the DS status in all participants.
Dementia status was assessed using International Statistical Classification of Diseases, 10th Revision research criteria [42].

All participants underwent standard physical, neurological and psychiatric screening, including routine blood tests (e.g. renal and liver function tests, red blood cell count and thyroid function tests) and clinical magnetic resonance imaging. We excluded people with a clinically detectable physical or psychiatric disorder affecting brain function (e.g. hypertension), a known history of birth trauma or head injury, or with an abnormal clinical magnetic resonance image (for example, as indicated by the presence of significant white matter hyperintensities). None of the participants were taking psychotropic medication at the time of the study. The project was approved by Multi-Centre Research Ethics Committee (MREC) and Local Research Ethics Committees (LREC), and after complete description of the study to the participants and their identified carers, written informed consent was obtained from them or if this was not possible, assent was obtained from their identified carers.

\section{${ }^{1} \mathrm{H}$ MRS data acquisition and analysis \\ ${ }^{1} \mathrm{H}$ MRS protocol}

The subjects were scanned using a 1.5 Tesla GE NV/i Signa MR System (General Electric, Milwaukee, WI, USA) at the Maudsley Hospital, London. 3D T1weighted volume images were acquired in the axial plane

Table 1 Demographic, MRI and ${ }^{1} \mathrm{H}$ MRS characteristics by group

\begin{tabular}{|c|c|c|c|c|}
\hline & Non-demented DS (DS-) & Demented DS (DS+) & Healthy controls (HC) & Significance \\
\hline$N=85$ & $n=35$ & $n=11$ & $n=39$ & \\
\hline \multicolumn{5}{|l|}{ Demographics, mean (percent) } \\
\hline Male no. & $26(74 \%)$ & $6(55 \%)$ & $24(62 \%)$ & $p=0.358^{a}$ \\
\hline Age, mean (SD) & $35(12)$ & $52(6)$ & $35(12)$ & $p<0.001^{b}$ \\
\hline \multicolumn{5}{|l|}{ Cognitive measures } \\
\hline CAMCOG (total) score & $56(22)$ & $32(21)$ & $119(3)$ & $p<0.001^{b}$ \\
\hline CAMCOG (short-term memory) score & $12(7)$ & $5(4)$ & $22(2)$ & $p<0.001^{b}$ \\
\hline \multicolumn{5}{|l|}{ MRI VOI proportions } \\
\hline Grey proportion (average R and L) & $0.76(0.07)$ & $0.75(0.11)$ & $0.72(0.08)$ & $p=0.187^{b}$ \\
\hline White proportion (average $\mathrm{R}$ and $\mathrm{L}$ ) & $0.24(0.07)$ & $0.25(0.11)$ & $0.28(0.08)$ & $p=0.187^{b}$ \\
\hline Mean CSF (R) & $0.13(0.07)$ & $0.15(0.04)$ & $0.07(0.04)$ & $p=0.000^{b}$ \\
\hline Mean CSF $(\mathrm{L})$ & $0.10(0.07)$ & $0.17(0.09)$ & $0.07(0.04)$ & $p=0.006^{b}$ \\
\hline \multicolumn{5}{|l|}{ Mean metabolite concentration } \\
\hline Glx (R hippocampus) & $38.89(6.13)$ & $41.04(4.16)$ & $38.49(7.03)$ & $p=0.309^{c}$ \\
\hline Glx (L hippocampus) & $36.51(5.25)$ & $36.56(7.20)$ & $36.59(5.72)$ & $p=0.955^{c}$ \\
\hline Glx (average of $\mathrm{R}$ and $\mathrm{L}$ ) & $38.14(5.61)$ & $38.41(4.71)$ & $37.57(5.16)$ & $p=0.853^{c}$ \\
\hline
\end{tabular}

$L$ left, $R$ right, CAMCOG Cambridge Cognitive Examination, VOI volume of interest.

${ }^{\text {a Chi-square. }}$

${ }^{\mathrm{b}}$ ANOVA.

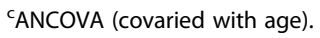


with $1.5-\mathrm{mm}$ contiguous sections using acquisition parameters chosen using a contrast simulation tool [43]. Repetition time (TR) was $13.8 \mathrm{~ms}$, inversion time (TI) $450 \mathrm{~ms}$, echo time (TE) $2.8 \mathrm{~ms}$ and the flip angle was $20^{\circ}$ with one data average and a $256 \times 256 \times 124$ voxel matrix. Acquisition time was $6 \mathrm{~min}, 27 \mathrm{~s}$.

${ }^{1} \mathrm{H}$ MRS voxels of interest measuring $20 \times 20 \times 15 \mathrm{~mm}^{3}$ $(6 \mathrm{ml})$ were defined in standard locations in the left and right hippocampi using a previously published method $[44,45]$. We chose hippocampal regions of interest as they were of particular relevance in DS and one of the earliest sites of change in AD. The anterior location of the voxel was defined as the coronal slice where the amygdala disappeared, extending posteriorly $20 \mathrm{~mm}$ and so covering the bulk of the hippocampus (Figure 1). The hippocampal volume of interest contained both grey and white matter and included some superior medial portions of the parahippocampal gyrus and the posterior portion of the amygdala.

A point resolved spectroscopy (PRESS) pulse sequence (TE 35 ms, TR $1500 \mathrm{~ms}, 256$ data averages and 2,048 points) with automated shimming and water suppression and excellent reproducibility [46] was used to obtain spectra from each voxel after CHESS water suppression with high signal-to-noise ratio and clearly resolved NAA, Cho, $\mathrm{mI}, \mathrm{Cr}+\mathrm{PCr}$ and Glx peaks among other metabolites. Non-water-suppressed data were also collected for water referencing, but data was not collected to measure metabolite $\mathrm{T} 1$ and $\mathrm{T} 2$ relaxation times for individual subjects due to the limited tolerance of DS subjects for MRI scanning. Results are expressed as relaxation time corrected ratios to unsuppressed water. Not all subjects had spectral

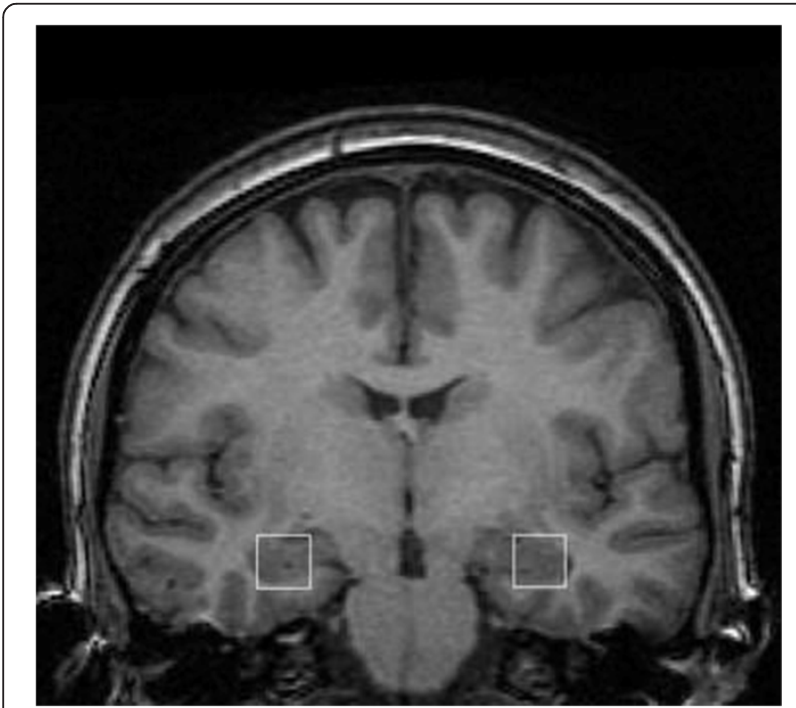

Figure 1 Coronal T1-weighted magnetic resonance image illustrating the location of the ${ }^{1} \mathrm{H}$ MRS voxels in the left and right hippocampi. data from both left and right hippocampi. No significant differences were found in the metabolite content between the right and the left side of the hippocampus. Therefore, we averaged the metabolite measures from the left and right hippocampi from the subjects which had data from both hemispheres.

\section{${ }^{1} \mathrm{H}$ MRS data analysis}

Differences in proportions of white and grey matter in the ${ }^{1} H M R S$ voxels may confound group differences in metabolite concentrations. Thus, to ensure that differences in tissue composition did not account for metabolic differences between subject groups, we segmented the SPGR volumes using Statistical Parametric Mapping (SPM) software (http://www.fil.ion.ucl.ac.uk/spm) to determine the percentage of grey matter, white matter and CSF within the MRS voxels after quality control of the images as described previously $[47,48]$. The position of the ${ }^{1} H M R S$ voxels relative to the segmented $3 \mathrm{D}$ dataset was determined automatically using an in-house software. T1 and T2 corrections were applied for each metabolite using literature values [49].

Spectra were processed using LCModel [50], and metabolite concentrations were automatically corrected for CSF contamination of the voxel by dividing by the tissue fraction of the MRS voxel determined using SPM. These corrected concentrations were then calibrated to absolute molar units with respect to a phantom of known concentration, which was scanned in the same scanning session as the subject, using a PRESS acquisition with the same TE and TR.

\section{Cognitive assessment}

Cognitive ability was measured using the Cambridge Cognitive Examination (CAMCOG) [51,52]. The CAMCOG has been validated for use with adults with DS [53] and provides a measure of general cognitive function, including measures of episodic memory (which is associated with hippocampal function), orientation, language, attention, praxis and executive function. The CAMCOG, developed originally to measure cognitive functioning in people with mild to moderate dementia, is less subject to floor effects and so found to be also appropriate for people with DS. For each participant, neuropsychological testing was completed within 6 months of scanning.

\section{Statistical analysis}

Statistical analysis was carried out using SPSS (SPSS 18.0 for Windows; SPSS Inc., Chicago, IL, USA). Comparisons between age and ${ }^{1} \mathrm{H}$ MRS Glx concentrations between the groups were made using univariate general linear models (GLM). Differences in gender distribution were tested for using a chi-squared test. Group differences in Glx concentrations were tested with one-way 
analysis of variance (ANOVA), with group as the betweensubject factor. There were no significant interactions between the side from which ${ }^{1} H$ MRS Glx concentrations were measured (left or right hippocampus) or gender and group. To verify that voxel composition was not obscuring group differences, we performed an ANOVA with corrected Glx as the dependent variable, Group (DS-, DS+, $\mathrm{HC}$ ) and Side (left vs. right) as a between-subject factor and covariates being voxel grey, white and CSF proportion. In this analysis, neither Group nor Group $\times$ Side were significant predictors of estimated Glx $(p=0.199$ and $p=0.550$ ) indicating that even controlling for voxel composition, there was no group difference in Glx in either left or right hippocampus. Therefore, mean hippocampal Glx concentrations were considered in the analysis with age used as a covariate.

For each of the groups, the relationship between hippocampal Glx concentrations and cognitive ability and memory (measured by the CAMCOG total and short-term memory scores) was examined using Pearson's productmoment correlation. Level of statistical significance was defined as $p<0.05$ (two tailed). Power calculations were performed using the mean Glx concentration differences between the groups in this study on G*Power version 3.1.5.

\section{Results}

The results are summarised in Table 1 and Figure 2. The DS+ group were older than both the DS- and healthy control groups. Therefore, age was added as a covariate in the analyses. As expected, the groups also differed in their CAMCOG (total cognition and short-term memory) scores-with the demented DS+ group having the lowest scores and the $\mathrm{HC}$ having the highest.

Grey and white matter composition of the MRS voxels did not differ between the groups, although there were differences between the groups for CSF composition. Overall, we found no significance between group differences in Glx concentrations. Furthermore, there was no correlation between hippocampal Glx concentration and cognitive ability and memory as measured by the CAMCOG (total and short-term memory) scores in either of the DS groups (see Table 2).

Due to our relatively small sample size of DS+, it is possible that we were underpowered to detect differences. Hence, we carried out a power analysis. This showed that it would have required 6,257 participants to provide $80 \%$ power to detect a significant difference in Glx between the groups at $p<0.05$ which would indicate a very low likelihood of a type 2 error accounting for our findings.

\section{Discussion}

Hippocampal Glx in DS and when compared with the general population

We found no significant between-group differences in hippocampal Glx concentration. The Glx findings in our

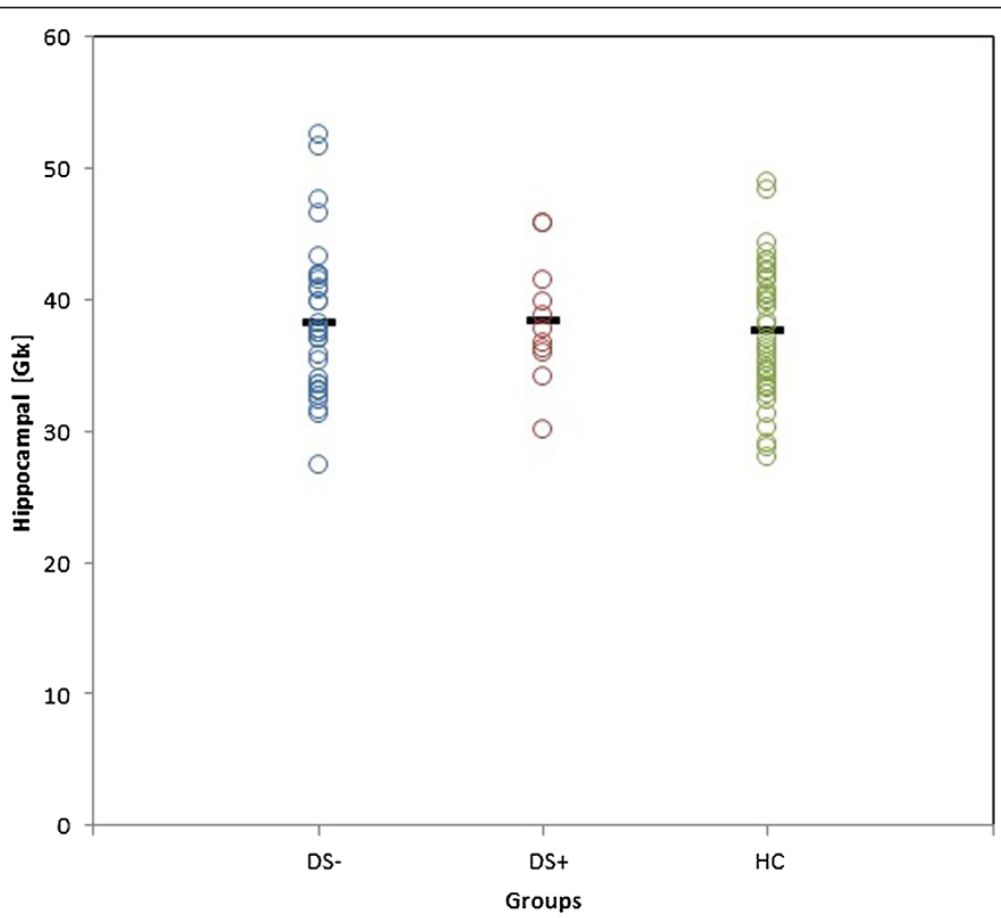

Figure 2 Scatter plot of average Glx concentrations of both hippocampi for all groups. No significant differences across groups ( $p=0.853)$. Glx glutamate-glutamine, DS- non-demented Down syndrome subjects, DS+ demented Down syndrome subjects, HC healthy controls. Note: horizontal bars represent the means for each group. 
Table 2 Correlation of cognitive measures with mean hippocampal Glx concentrations for each group

\begin{tabular}{lll}
\hline & $\begin{array}{l}\text { Non-demented } \\
\text { DS (DS-) }\end{array}$ & $\begin{array}{l}\text { Demented } \\
\text { DS (DS+) }\end{array}$ \\
\hline CAMCOG (total) score & $r=0.13(p=0.464)$ & $r=-0.225(p=0.715)$ \\
$\begin{array}{l}\text { CAMCOG (short-term } \\
\text { memory) score }\end{array}$ & $r=0.123(p=0.497)$ & $r=-0.296(p=0.569)$ \\
\hline
\end{tabular}

study are consistent with (and extends into demented individuals) 1) an earlier ${ }^{1} \mathrm{H}$ MRS study of DS children that reported no differences in temporal lobe Glx concentration [36] and 2) postmortem studies of adult DS brains that had not detected any increase in temporal lobe glutamate [29]. Hence, our findings suggest that the hippocampal glutamatergic neurotransmitter system (at least as measured using Glx at 1.5 Tesla) is not significantly dysregulated in people with DS-and so is not the main cause for the ID (or AD) typically found in the disorder.

Other factors, therefore, most likely play a greater role. These may include dysregulation of acetylcholine (ACh) [54], dopamine [55], GABA [56] and serotonin (5-HT) [57]; and/or brain metabolites such as $\mathrm{mI}$ [10]. ACh has long been known to be a critical mediator of learning and memory [58], and cholinergic neurons are particularly affected in AD [54]. Dopamine [55] and GABA modulate memory, and drugs that act as inverse agonists at the GABA(A) receptor have shown promise in enhancing memory function [56]. $\mathrm{mI}$ is elevated in the hippocampus of DS- adults and is negatively correlated with their cognitive ability [10] and further increased in DS+ individuals [11].

\section{Hippocampal Glx in demented DS+ versus $A D$ in the general population}

In this study, we did not find any differences in hippocampal Glx concentration between DS+ individuals when compared to either their DS- counterparts or healthy controls. The DS+ group were significantly older than the DS- and HC groups.

To the best of our knowledge, there are no previous studies that have examined hippocampal Glx in people with DS and AD. Our findings (albeit in a limited sample) are consistent with some (but not all) ${ }^{1} \mathrm{H}$ MRS studies of $\mathrm{AD}$ in the general population. For instance, some reported no differences in the Glx concentration of temporoparietal grey matter between $\mathrm{AD}$ individuals and healthy controls [59], whereas others reported decreased glutamate in the right hippocampus [60]. Thus, the hippocampal metabolic changes in people with $\mathrm{DS}$ and $\mathrm{AD}$ may differ from those of non-DS people with AD.

However, our initial evidence taken together with the work of others suggests that the situation may be different in people with DS. For instance, two recent randomised double-blind placebo-controlled trials which investigated the efficacy of memantine in DS people found limited effect of treatment with memantine on cognitive or functional outcomes. Boada et al. compared the effect of 16-week treatment with either memantine or placebo on cognitive and adaptive functions of 40 young adults with DS and found no significant differences between the memantine and placebo groups on the two primary outcome measures involving episodic memory [61]. In the study by Hanney et al. which compared adults with DS with and without dementia and involved 88 patients receiving memantine and 85 patients receiving placebo showed that both groups declined in cognitive and functional ability but rates did not differ between groups for any cognitive or functional outcomes at 52 weeks of treatment [62]. Therefore, in people with DS, dysregulation of glutamatergic neurotransmission and related glutamatemediated excitotoxicity may not be the major pathway for the development of either ID or AD. This has implications for the development of new treatments.

Various risk factors and hypotheses for the pathogenesis of AD in DS have been proposed [63] including the role of $\beta$-amyloid accumulation in the DS brain [6]. However, a recent in vivo study using positron emission tomography (PET) showed that DS- individuals have comparable concentrations of $\beta$-amyloid in the brain as compared with non-DS people with AD [64] and would suggest that there are factors other than $\beta$-amyloid loading which are important for the development of $\mathrm{AD}$ in people with DS.

These other factors may include apolipoprotein E $\varepsilon 4$ allele [65], extended tau haplotype [66], dual-specificity tyrosine-regulated kinase 1A (DYRK1A) and calcipressin [67], tetranucleotide repeat in intron 7 of the APP [68], estradiol [69], $\mathrm{Cu} / \mathrm{Zn}$ superoxide dismutase (SOD1) [70], neuroinflammation [71] and serotonergic dysfunction [8,72]. In particular, $\mathrm{mI}$ which has been associated with dementia in the general population [73] and may also have particular relevance in people with DS as the $\mathrm{Na}^{+}$/myo-inositol co-transporter gene (SCL5A3) located on chromosome 21 [74] has been shown in our previous work to be increased in the hippocampus of DS- [10] and further increased in DS+ [11] may point to a potential role of $\mathrm{mI}$ in the cascade of events that lead to AD in people with DS.

\section{Limitations}

Our study had a relatively small sample size, and we included relatively few demented DS+ participants. However, due to the small differences between the groups, it would have required an unrealistically large number of participants in the study to show an effect. A sample size calculation based on the effect sizes from this study showed that it would have required 6,257 participants to provide $80 \%$ power to detect a significant difference between the groups. People with DS are a difficult population to recruit 
to studies, and they all have ID and can have difficulty tolerating the demands of the scanning procedure and cognitive assessments. Furthermore, the participants in our study were not medicated or sedated prior to their brain scans to facilitate the scan procedure.

The study was conducted at relatively low field strength $(1.5 \mathrm{~T})$, and glutamate was expressed as Glx rather than as glutamate and glutamine separately. Glutamate, glutamine and GABA exist in a metabolite shuttle known as the glutamate/GABA-glutamine cycle. Measuring Glx on its own may not have detected changes in the metabolite shuttle as GABA could not be accurately measured at low field strength. It is possible that Glx metabolite changes may have occurred in brain regions that were not examined in this study, but the hippocampus was chosen due to its known involvement in memory and early involvement in AD. We did not examine other brain regions critical to higher cognitive function owing to limitations in patient compliance and time constraints. Despite that, we managed to scan a sizeable number of non-demented DS participants in this study and did not find any differences in Glx concentration compared to healthy controls. We have previously reported differences in myo-inositol concentration in a similar number of participants which would indicate that even if there were differences in Glx concentrations between the groups, these differences are much less pronounced than those affecting myo-inositol.

Future studies involving larger numbers of DS+ participants, using higher field strength ${ }^{1} \mathrm{H}$ MRS and using multi-voxel ${ }^{1} \mathrm{H}$ MRS approaches will allow better spectral segregation of glutamate and glutamine and measurement of GABA as well as the examination of other regions of the brain critical to higher cognitive function.

\section{Conclusions}

We found no evidence that DS individuals (with or without dementia) have significant dysregulation of glutamatergic neurotransmission. Other factors may be more crucial in the development of both ID and AD in people with DS.

\section{Competing interests}

The authors declare that they have no competing interests.

\section{Authors' contributions}

$F B, V P$ and $M H$ were involved in recruitment to the study. FB, ED and AS were involved in data acquisition and image analysis. RM, SL, KM, AS and DM were involved in the study conception and design. GT, JH, AS and DM were involved in data interpretation. GT drafted the manuscript, and AS and DM edited the manuscript. DM supervised the whole project. All authors read and approved the final manuscript.

\section{Acknowledgements}

This project was generously supported by the South London and Maudsley National Health Service (NHS) Foundation Trust (National Division), the Baily Thomas Charitable Fund, the Sackler Institute for Neurodevelopmental Translational Research, the NIHR Biomedical Research Centre and NIHR Biomedical Research Unit for Dementia at the South London and Maudsley
NHS Foundation Trust, and Institute of Psychiatry, King's College London. We especially thank the individuals with Down syndrome and their families and carers for taking part in the study.

\section{Author details}

${ }^{1}$ Sackler Institute for Translational Neurodevelopment, Department of Forensic and Neurodevelopmental Sciences, Institute of Psychiatry, King's College London, London, UK. ${ }^{2}$ Southern Health NHS Foundation Trust, North Hampshire Community Learning Disability Service, Winchester, Hampshire, UK. ${ }^{3}$ Greenfields Monyhull Hospital, Kings Norton, Birmingham, UK. ${ }^{4}$ Northumberland Tyne and Wear NHS Foundation Trust, Northgate Hospital, Morpeth, Northumberland, UK. ${ }^{5}$ Department of Psychology, Institute of Psychiatry, King's College London, London, UK. 'Department of Old Age Psychiatry, Institute of Psychiatry, King's College London, London, UK. ${ }^{7}$ Department of Psychiatry, Royal College of Surgeons in Ireland, Dublin, Ireland. ${ }^{8}$ Department of Neuroimaging, Institute of Psychiatry, King's College London, London, UK. ${ }^{9} \mathrm{NIHR}$ Biomedical Research Centre for Mental Health and Biomedical Research Unit for Dementia, South London and Maudsley NHS Foundation Trust, London, UK.

Received: 24 July 2014 Accepted: 4 November 2014

Published: 27 November 2014

\section{References}

1. Wisniewski KE: Down syndrome children often have brain with maturation delay, retardation of growth, and cortical dysgenesis. Am J Med Genet Suppl 1990, 7:274-281.

2. Schupf N, Sergievsky GH: Genetic and host factors for dementia in Down's syndrome. Br J Psychiatry 2002, 180:405-410.

3. Visser FE, Aldenkamp AP, van Huffelen AC, Kuilman M, Overweg J, van Wijk J: Prospective study of the prevalence of Alzheimer-type dementia in institutionalized individuals with Down syndrome. Am J Ment Retard 1997, 101:400-412.

4. Margallo-Lana ML, Moore PB, Kay DW, Perry RH, Reid BE, Berney TP, Tyrer SP: Fifteen-year follow-up of 92 hospitalized adults with Down's syndrome: incidence of cognitive decline, its relationship to age and neuropathology. J Intellect Disabil Res 2007, 51:463-477.

5. Sheehan R, Ali A, Hassiotis A: Dementia in intellectual disability. Curr Opin Psychiatry 2014, 27:143-148.

6. Prasher VP, Farrer MJ, Kessling AM, Fisher EM, West RJ, Barber PC, Butler AC: Molecular mapping of Alzheimer-type dementia in Down's syndrome. Ann Neurol 1998, 43:380-383.

7. Whittle N, Sartori SB, Dierssen M, Lubec G, Singewald N: Fetal Down syndrome brains exhibit aberrant levels of neurotransmitters critical for normal brain development. Pediatrics 2007, 120:e1465-e1471.

8. Bianchi P, Ciani E, Guidi S, Trazzi S, Felice D, Grossi G, Fernandez M, Giuliani A, Calza L, Bartesaghi R: Early pharmacotherapy restores neurogenesis and cognitive performance in the Ts65Dn mouse model for Down syndrome. J Neurosci 2010, 30:8769-8779.

9. Belichenko PV, Masliah E, Kleschevnikov AM, Villar AJ, Epstein CJ, Salehi A, Mobley WC: Synaptic structural abnormalities in the Ts65Dn mouse model of Down syndrome. J Comp Neurol 2004, 480:281-298.

10. Beacher F, Simmons A, Daly E, Prasher V, Adams C, Margallo-Lana ML, Morris R, Lovestone S, Murphy K, Murphy DG: Hippocampal myo-inositol and cognitive ability in adults with Down syndrome: an in vivo proton magnetic resonance spectroscopy study. Arch Gen Psychiatry 2005, 62:1360-1365.

11. Lamar M, Foy CM, Beacher F, Daly E, Poppe M, Archer N, Prasher V, Murphy KC, Morris RG, Simmons A, Lovestone S, Murphy DG: Down syndrome with and without dementia: an in vivo proton magnetic resonance spectroscopy study with implications for Alzheimer's disease. Neuroimage 2011, 57:63-68.

12. Robbins TW, Murphy ER: Behavioural pharmacology: 40+ years of progress, with a focus on glutamate receptors and cognition. Trends Pharmacol Sci 2006, 27:141-148.

13. Cull-Candy S, Brickley S, Farrant M: NMDA receptor subunits: diversity, development and disease. Curr Opin Neurobiol 2001, 11:327-335.

14. McKernan MG, Shinnick-Gallagher P: Fear conditioning induces a lasting potentiation of synaptic currents in vitro. Nature 1997, 390:607-611. 
15. Rogan MT, Staubli UV, LeDoux JE: AMPA receptor facilitation accelerates fear learning without altering the level of conditioned fear acquired. J Neurosci 1997, 17:5928-5935.

16. Doraiswamy PM: Alzheimer's disease and the glutamate NMDA receptor. Psychopharmacol Bull 2003, 37:41-49.

17. Sucher NJ, Awobuluyi M, Choi YB, Lipton SA: NMDA receptors: from genes to channels. Trends Pharmacol Sci 1996, 17:348-355.

18. Francis PT, Sims NR, Procter AW, Bowen DM: Cortical pyramidal neurone loss may cause glutamatergic hypoactivity and cognitive impairment in Alzheimer's disease: investigative and therapeutic perspectives. J Neurochem 1993, 60:1589-1604.

19. Francis PT: The interplay of neurotransmitters in Alzheimer's disease. CNS Spectrosc 2005, 10:6-9.

20. Marlatt MW, Webber KM, Moreira PI, Lee HG, Casadesus G, Honda K, Zhu X Perry G, Smith MA: Therapeutic opportunities in Alzheimer disease: one for all or all for one? Curr Med Chem 2005, 12:1137-1147.

21. Lipton SA: Failures and successes of NMDA receptor antagonists: molecular basis for the use of open-channel blockers like memantine in the treatment of acute and chronic neurologic insults. NeuroRx 2004, 1:101-110.

22. Glodzik L, King KG, Gonen O, Liu S, De Santi S, de Leon MJ: Memantine decreases hippocampal glutamate levels: a magnetic resonance spectroscopy study. Prog Neuropsychopharmacol Biol Psychiatry 2008, 32:1005-1012

23. Tariot PN, Farlow MR, Grossberg GT, Graham SM, McDonald S, Gergel I: Memantine treatment in patients with moderate to severe Alzheimer disease already receiving donepezil: a randomized controlled trial. JAMA 2004, 291:317-324

24. Kurt MA, Davies DC, Kidd M, Dierssen M, Florez J: Synaptic deficit in the temporal cortex of partial trisomy 16 (Ts65Dn) mice. Brain Res 2000, 858:191-197.

25. Tordera RM, Totterdell S, Wojcik SM, Brose N, Elizalde N, Lasheras B, Del Rio J: Enhanced anxiety, depressive-like behaviour and impaired recognition memory in mice with reduced expression of the vesicular glutamate transporter 1 (VGLUT1). Eur J Neurosci 2007, 25:281-290.

26. Siarey RJ, Kline-Burgess A, Cho M, Balbo A, Best TK, Harashima C, Klann E, Galdzicki Z: Altered signaling pathways underlying abnormal hippocampal synaptic plasticity in the Ts65Dn mouse model of Down syndrome. J Neurochem 2006, 98:1266-1277.

27. Begni B, Brighina L, Fumagalli L, Andreoni S, Castelli E, Francesconi C, Del Bo R, Bresolin N, Ferrarese C: Altered glutamate uptake in peripheral tissues from Down syndrome patients. Neurosci Lett 2003, 343:73-76.

28. Reynolds GP, Warner CE: Amino acid neurotransmitter deficits in adult Down's syndrome brain tissue. Neurosci Lett 1988, 94:224-227.

29. Seidl R, Cairns N, Singewald N, Kaehler ST, Lubec G: Differences between GABA levels in Alzheimer's disease and Down syndrome with Alzheimer-like neuropathology. Naunyn Schmiedebergs Arch Pharmacol 2001, 363:139-145.

30. Risser D, Lubec G, Cairns N, Herrera-Marschitz M: Excitatory amino acids and monoamines in parahippocampal gyrus and frontal cortical pole of adults with Down syndrome. Life Sci 1997, 60:1231-1237.

31. Miller BL: A review of chemical issues in $1 \mathrm{H}$ NMR spectroscopy: N-acetylL-aspartate, creatine and choline. NMR Biomed 1991, 4:47-52.

32. Bates TE, Strangward M, Keelan J, Davey GP, Munro PM, Clark JB: Inhibition of $\mathrm{N}$-acetylaspartate production: implications for $1 \mathrm{H}$ MRS studies in vivo. Neuroreport 1996, 7:1397-1400

33. Novotny EJ Jr, Fulbright RK, Pearl PL, Gibson KM, Rothman DL: Magnetic resonance spectroscopy of neurotransmitters in human brain. Ann Neurol 2003, 54(Suppl 6):S25-S31.

34. Bak LK, Schousboe A, Waagepetersen HS: The glutamate/GABA-glutamine cycle: aspects of transport, neurotransmitter homeostasis and ammonia transfer. J Neurochem 2006, 98:641-653.

35. Smigielska-Kuzia J, Sobaniec W: Brain metabolic profile obtained by proton magnetic resonance spectroscopy HMRS in children with Down syndrome. Adv Med Sci 2007, 52(Suppl 1):183-187.

36. Smigielska-Kuzia J, Bockowski L, Sobaniec W, Kulak W, Sendrowski K: Amino acid metabolic processes in the temporal lobes assessed by proton magnetic resonance spectroscopy (1H MRS) in children with Down syndrome. Pharmacol Rep 2010, 62:1070-1077.

37. Aylward EH, Li Q, Honeycutt NA, Warren AC, Pulsifer MB, Barta PE, Chan MD Smith PD, Jerram M, Pearlson GD: MRI volumes of the hippocampus and amygdala in adults with Down's syndrome with and without dementia. Am J Psychiatry 1999, 156:564-568.

38. Beacher F, Daly E, Simmons A, Prasher V, Morris R, Robinson C, Lovestone S, Murphy K, Murphy DG: Alzheimer's disease and Down's syndrome: an in vivo MRI study. Psychol Med 2009, 39:675-684

39. Tan GMY, Murphy DGM: Brain MRI findings in down syndrome and dementia. Med Men Geist Mehrf Beh 2011, 8:30-38.

40. Ball MJ, Nuttall K: Neurofibrillary tangles, granulovacuolar degeneration, and neuron loss in down syndrome: quantitative comparison with Alzheimer dementia. Ann Neurol 1980, 7:462-465.

41. Braak H, Braak E: Morphological criteria for the recognition of Alzheimer's disease and the distribution pattern of cortical changes related to this disorder. Neurobiol Aging 1994, 15:355-356. discussion 379-380.

42. WHO: The ICD-10 Classification of Mental and Behavioural Disorders. Clinical Descriptions and Diagnostic Guidelines. Geneva: World Health Organization; 1992.

43. Simmons A, Arridge SR, Barker GJ, Williams SC: Simulation of MRI cluster plots and application to neurological segmentation. Magn Reson Imaging 1996, 14:73-92.

44. Robertson DM, van Amelsvoort T, Daly E, Simmons A, Whitehead M, Morris RG, Murphy KC, Murphy DG: Effects of estrogen replacement therapy on human brain aging: an in vivo 1H MRS study. Neurology 2001, 57:2114-2117.

45. Cutter WJ, Daly EM, Robertson DM, Chitnis XA, van Amelsvoort TA, Simmons A, Ng W, Williams BS, Shaw P, Conway GS, Skuse DH, Collier DA, Craig M, Murphy DG: Influence of $X$ chromosome and hormones on human brain development: a magnetic resonance imaging and proton magnetic resonance spectroscopy study of Turner syndrome. Biol Psychiatry 2006, 59:273-283.

46. Simmons A, Smail M, Moore E, Williams SC: Serial precision of metabolite peak area ratios and water referenced metabolite peak areas in proton MR spectroscopy of the human brain. Magn Reson Imaging 1998, 16:319-330.

47. Simmons A, Westman E, Muehlboeck S, Mecocci P, Vellas B, Tsolaki M, Kloszewska I, Wahlund LO, Soininen H, Lovestone S, Evans A, Spenger C: MRI measures of Alzheimer's disease and the AddNeuroMed study. Ann N Y Acad Sci 2009, 1180:47-55.

48. Simmons A, Westman E, Muehlboeck S, Mecocci P, Vellas B, Tsolaki M, Kloszewska I, Wahlund LO, Soininen H, Lovestone S, Evans A, Spenger C: The AddNeuroMed framework for multi-centre MRI assessment of Alzheimer's disease: experience from the first 24 months. Int J Geriatr Psychiatry 2011, 26:75-82.

49. Christiansen $P$, Toft $P$, Larsson HB, Stubgaard M, Henriksen O: The concentration of $\mathrm{N}$-acetyl aspartate, creatine + phosphocreatine, and choline in different parts of the brain in adulthood and senium. Magn Reson Imaging 1993, 11:799-806.

50. Provencher SW: Estimation of metabolite concentrations from localized in vivo proton NMR spectra. Magn Reson Med 1993, 30:672-679.

51. Huppert FA, Brayne C, Gill C, Paykel ES, Beardsall L: CAMCOG-a concise neuropsychological test to assist dementia diagnosis: socio-demographic determinants in an elderly population sample. Br J Clin Psychol 1995, 34(Pt 4):529-541.

52. Roth M, Huppert FA, Mountjoy CQ, Tym E: The Revised Cambridge Examination for Mental Disorders of the Elderly. Cambridge: Cambridge University Press; 1998.

53. Hon J, Huppert FA, Holland AJ, Watson P: Neuropsychological assessment of older adults with Down's syndrome: an epidemiological study using the Cambridge Cognitive Examination (CAMCOG). Br J Clin Psychol 1999, 38(Pt 2):155-165.

54. Muir JL: Acetylcholine, aging, and Alzheimer's disease. Pharmacol Biochem Behav 1997, 56:687-696.

55. Arnsten AF, Cai JX, Murphy BL, Goldman-Rakic PS: Dopamine D1 receptor mechanisms in the cognitive performance of young adult and aged monkeys. Psychopharmacology (Berl) 1994, 116:143-151.

56. Ballard TM, Knoflach F, Prinssen E, Borroni E, Vivian JA, Basile J, Gasser R, Moreau JL, Wettstein JG, Buettelmann B, Knust H, Thomas AW, Trube G, Hernandez MC: RO4938581, a novel cognitive enhancer acting at GABAA alpha5 subunit-containing receptors. Psychopharmacology (Berl) 2009, 202:207-223.

57. Buhot MC, Martin S, Segu L: Role of serotonin in memory impairment. Ann Med 2000, 32:210-221 
58. Drachman DA: Memory and cognitive function in man: does the cholinergic system have a specific role? Neurology 1977, 27:783-790.

59. Ernst T, Chang L, Melchor R, Mehringer CM: Frontotemporal dementia and early Alzheimer disease: differentiation with frontal lobe H-1 MR spectroscopy. Radiology 1997, 203:829-836.

60. Rupsingh R, Borrie M, Smith M, Wells JL, Bartha R: Reduced hippocampal glutamate in Alzheimer disease. Neurobiol Aging 2011, 32:802-810.

61. Boada R, Hutaff-Lee C, Schrader A, Weitzenkamp D, Benke TA, Goldson EJ, Costa AC: Antagonism of NMDA receptors as a potential treatment for Down syndrome: a pilot randomized controlled trial. Trans/ Psychiatry 2012, 2:e141.

62. Hanney M, Prasher V, Williams N, Jones EL, Aarsland D, Corbett A, Lawrence D, Yu LM, Tyrer S, Francis PT, Johnson T, Bullock R, Ballard C: Memantine for dementia in adults older than 40 years with Down's syndrome (MEADOWS): a randomised, double-blind, placebo-controlled trial. Lancet 2012, 379:528-536.

63. Tan GMY, Murphy DGM: Down syndrome: genetic and clinical overlap with dementia. In Principles and Practice of Geriatric Psychiatry. 3rd edition. Edited by Abou-Saleh MM, Katona CLE, Kumar A. New York: Wiley; 2011:281-286

64. Nelson LD, Siddarth P, Kepe V, Scheibel KE, Huang SC, Barrio JR, Small GW: Positron emission tomography of brain \{beta\}-amyloid and tau levels in adults with Down syndrome. Arch Neurol 2011, 68:768-774.

65. Coppus AM, Evenhuis HM, Verberne GJ, Visser FE, Arias-Vasquez A, Sayed-Tabatabaei FA, Vergeer-Drop J, Eikelenboom P, van Gool WA, van Duijn CM, Coppus AMW: The impact of apolipoprotein E on dementia in persons with Down's syndrome. Neurobiol Aging 2008, 29:828-835.

66. Jones EL, Margallo-Lana M, Prasher VP, Ballard CG: The extended tau haplotype and the age of onset of dementia in Down syndrome. Dement Geriatr Cogn Disord 2008, 26:199-202.

67. Kimura R, Kamino K, Yamamoto M, Nuripa A, Kida T, Kazui H, Hashimoto R, Tanaka T, Kudo T, Yamagata H, Tabara Y, Miki T, Akatsu H, Kosaka K, Funakoshi E, Nishitomi K, Sakaguchi G, Kato A, Hattori H, Uema T, Takeda M: The DYRK1A gene, encoded in chromosome 21 Down syndrome critical region, bridges between beta-amyloid production and tau phosphorylation in Alzheimer disease. Hum Mol Genet 2007, 16:15-23.

68. Margallo-Lana M, Morris CM, Gibson AM, Tan AL, Kay DW, Tyrer SP, Moore BP, Ballard CG, Kay DWK: Influence of the amyloid precursor protein locus on dementia in Down syndrome. Neurology 2004, 62:1996-1998.

69. Schupf N, Winsten S, Patel B, Pang D, Ferin M, Zigman WB, Silverman W, Mayeux R: Bioavailable estradiol and age at onset of Alzheimer's disease in postmenopausal women with Down syndrome. Neurosci Lett 2006, 406:298-302.

70. Bush $\mathrm{A}$, Beail N: Risk factors for dementia in people with Down syndrome: issues in assessment and diagnosis. Am J Ment Retard 2004, 109:83-97.

71. Carta MG, Serra P, Ghiani A, Manca E, Hardoy MC, Del Giacco GS, Diaz G, Carpiniello B, Manconi PE: Chemokines and pro-inflammatory cytokines in Down's syndrome: an early marker for Alzheimer-type dementia? Psychother Psychosom 2002, 71:233-236.

72. Whitaker-Azmitia PM: Serotonin and brain development: role in human developmental diseases. Brain Res Bull 2001, 56:479-485.

73. Schott JM, Frost C, MacManus DG, Ibrahim F, Waldman AD, Fox NC: Short echo time proton magnetic resonance spectroscopy in Alzheimer's disease: a longitudinal multiple time point study. Brain 2010, 133:3315-3322.

74. Berry GT, Mallee JJ, Kwon HM, Rim JS, Mulla WR, Muenke M, Spinner NB: The human osmoregulatory $\mathrm{Na}+$ /myo-inositol cotransporter gene (SLC5A3): molecular cloning and localization to chromosome 21. Genomics 1995, 25:507-513.

doi:10.1186/1866-1955-6-42

Cite this article as: Tan et al:: Hippocampal glutamate-glutamine (GIx) in adults with Down syndrome: a preliminary study using in vivo proton magnetic resonance spectroscopy ('H MRS). Journal of Neurodevelopmental Disorders 2014 6:42.

\section{Submit your next manuscript to BioMed Central and take full advantage of:}

- Convenient online submission

- Thorough peer review

- No space constraints or color figure charges

- Immediate publication on acceptance

- Inclusion in PubMed, CAS, Scopus and Google Scholar

- Research which is freely available for redistribution

Submit your manuscript at www.biomedcentral.com/submit
C Biomed Central 